\title{
Update on Bone Marrow Collection and Stem Cell Transplantation
}

\author{
Ming $\mathrm{Li}^{1}$, Kequan $\mathrm{Guo}^{2}$ and Susumu Ikehara ${ }^{1 *}$
}

${ }^{1}$ Department of Stem Cell Disorders, Kansai Medical University, Hirakata City, Osaka, Japan

${ }^{2}$ Department of Cardiac Surgery, Beijing Anzhen Hospital affiliated to Capital Medical University, Beijing, China

\begin{abstract}
Bone marrow transplantation (BMT) is a powerful strategy for the treatment of leukemia, aplastic anemia, congenital immunodeficiency and autoimmune diseases. In humans, bone marrow cells (BMCs) have usually been collected by multiple bone marrow aspirations from the iliac crest. We have established a new "perfusion" method for collecting BMCs with minimal contamination with the peripheral blood using the long bones of cynomolgus monkeys. This method has proven to be a simple and safe method for harvesting BMCs and reduces the risk of acute graft versus host disease in allogeneic BMT. Intra-bone marrow-BMT (IBM-BMT) provides distinct advantages because it recruits donor-derived hematopoietic stem cells and mesenchymal stem cells. IBM-BMT has been shown to currently be the best strategy for allogeneic BMT. Here we review the perfusion method (for harvesting BMCs) and IBM-BMT (for their transplantation) and show that this combination will become a powerful new clinical strategy for allogeneic BMT.
\end{abstract}

Keywords: Perfusion method; Intra-bone marrow-bone marrow transplantation; Bone marrow cells; Allogeneic bone marrow transplantation; Graft versus host disease

Abbreviations: AM: Aspiration Method; BMT: Bone Marrow Transplantation; BM: Bone Marrow; BMCs: Bone Marrow Cells; GvHD: Graft Versus-host Disease; HSCs: Hematopoietic Stem Cells; IBM-BMT: Intra-bone Marrow-BMT; IV-BMT: Intravenously Injected-BMT; MHC: Major Histocompatibility Complex; MSCs: Mesenchymal Stem Cells; PM: Perfusion Method

\section{Introduction}

Bone marrow transplantation (BMT) is a powerful strategy for the treatment of hematologic disorders, including leukemia and autoimmune diseases [1-3]. Furthermore, gene therapy and organ transplantation have been performed using bone marrow cells (BMCs) [4-8]. We have established a new perfusion method for collecting BMCs using the long bones of cynomolgus monkeys [9]. This method is simple, safe and is better for obtaining pure BMCs, resulting in a decreased incidence of acute graft versus-host disease (GvHD) in allogeneic BMT.

In animal experiments, intra-bone marrow-BMT (IBM-BMT) has been shown to efficiently recruit not only donor-derived hematopoietic stem cells (HSCs) but also mesenchymal stem cells (MSCs) $[5,10,11]$. HSCs can normally proliferate in major histocompatibility complex (MHC)-compatible MSCs even in allogeneic microenvironments. One report has suggested the potential of mesenchymal stoma cells as a novel cell therapy to prevent allograft rejection and interstitial fibrosis/ tubular atrophy after kidney transplantation [12].

\section{Aspiration Method (AM) and Perfusion Method (PM) for Harvesting BMCs}

In humans, BMT is conventionally carried out by first collecting BMCs using multiple bone marrow (BM) aspirations from the iliac crest according to the method established by Thomas et al. [13]. The $\mathrm{BM}$ needles are inserted into the iliac bones more than 100 times. However, when using this AM, the BMCs are contaminated with peripheral blood with the result that there are more than $20 \%$ of T cells in the BMCs, which in turn leads to the induction of GvHD. When the thus-collected cells are intravenously injected (IV-BMT), most become trapped in the lung and only a few are able to migrate to the BM [14].
Nonhuman primates have similar stem and progenitor cell dynamics to humans and have been invaluable in developing and assessing new therapeutic transplant approaches for the treatment of human diseases [15-17]. The nonhuman primate studies closely model a clinical setting and should have broad applications for HSC gene therapy targeting human diseases of malignant, genetic and infectious nature [18]. Monkey mesenchymal stem cells (MSCs) have been shown to have similar features with human MSCs, thus providing important information for human therapies $[19,20]$.

Using cynomolgus monkeys, we have established a new BMC harvesting method, which we call the PM (Figure 1A). This method minimizes the contamination of BMCs with T cells. Briefly, two needles are inserted into a long bone such as the humerus or femur. The end of the extension tube is connected to one needle and the other end is placed in a syringe containing $0.5 \mathrm{~mL}$ heparin. The other needle is connected to a syringe containing $30 \mathrm{~mL}$ of saline, and the saline is then pushed gently from the syringe into the medullary cavity to flush out the BM. The saline containing the BM fluid is then collected [14]. There is significantly less contamination with $\mathrm{T}$ cells when using the PM $(<10 \%)$ than with the conventional AM $(>20 \%)$. Furthermore, the number and progenitor activities of the cells harvested using the PM are greater than when using the conventional AM [9]. The loss of some important cells such as MSCs during the process of T cell-depletion is inevitable when whole BMCs are contaminated with a high percentage of T cells, such as when the BMCs are collected using the AM. In this case, $\mathrm{T}$ cells from the peripheral blood contaminate the BMCs, leading to undesirable results despite the use of various treatments such as anti-T cell Abs and immunosuppressants. However, with the PM, there

*Corresponding author: Susumu Ikehara, MD, Ph.D, Professor of Department of Stem Cell Disorders, Kansai Medical University, 2-5-1 Shinmachi, Hirakata City, Osaka 573-1010, Japan, Tel: 81-72-804-2451; Fax: 81-72-804-2454; E-mail: ikehara@hirakata.kmu.ac.jp

Received December 17, 2013; Accepted January 02, 2014; Published January 04, 2014

Citation: Li M, Guo K, Ikehara S (2014) Update on Bone Marrow Collection and Stem Cell Transplantation. J Stem Cell Res Ther 4: 156. doi:10.4172/21577633.1000156

Copyright: ( $2014 \mathrm{Li} \mathrm{M}$, et al. This is an open-access article distributed under the terms of the Creative Commons Attribution License, which permits unrestricted use, distribution, and reproduction in any medium, provided the original author and source are credited. 
A

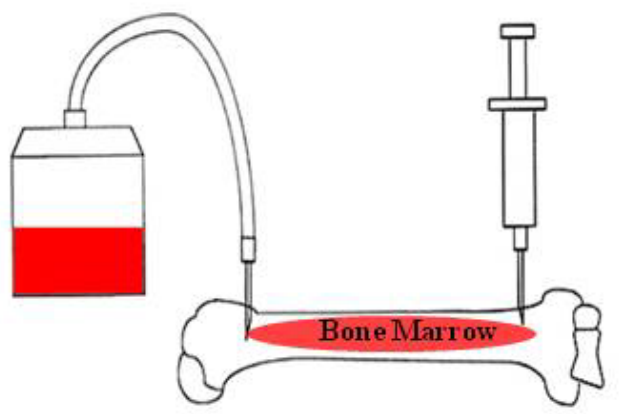

Perfusion Method for Harvesting BMCs
$\mathrm{B}$

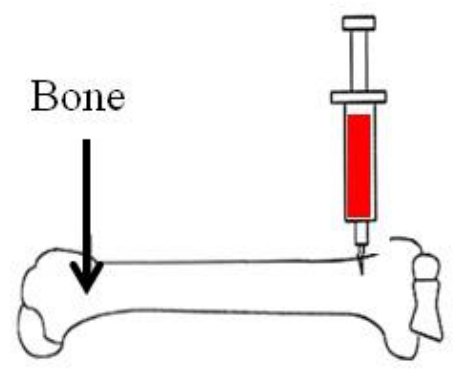

IBM-BMT

Figure 1: A New Method for Harvesting BMCs and IBM-BMT. (A) Perfusion method for harvesting BMCs. (B ) IBM-BMT.

is substantially less contamination with mature $\mathrm{T}$ cells, as confirmed by the RBC: WBC and lymphocyte:granulocyte ratios, which are significantly lower using the PM than the AM. BMCs collected using the PM contain more immature cells, such as myeloblasts and promyelocytes, than those collected by the AM. Moreover, CFU-C assays show that a higher percentage of hematopoietic progenitor cells can be obtained using the PM than AM (Table 1), again due to the low level of contamination with the peripheral blood. Enriched progenitor activity in the BMCs collected using the PM is advantageous for the recipients, since short-term reconstitution by donor cells can be attributed to these progenitors.

Although the number of BMCs decreases in the long bones with age, there is red BM in the ilium, even in older human subjects. BMCs harvested from the ilium of aged donors by the perfusion method can be used for BMT across major histocompatibility complex (MHC) barriers and for organ transplantation (combined with BMT) if the donors are brain dead. BMCs collected using the PM were transplanted directly into the bone marrow cavities of the long bones of recipient cynomolgus monkeys that had been pretreated with irradiation. IBMBMT was performed on both right and left humeri rather than tibiae in the case of these monkeys [21].

\section{IBM-BMT}

BMT can be used to treat hematopoietic disorders, metabolic disorders and autoimmune diseases [22-24]. IBM-BMT (Figure 1B) has been proven to be more effective than IV-BMT [25], since it can replace not only the HSCs and MSCs to be recruited, thereby preventing the risk of graft rejection, but also allows the use of a mild conditioning regimen. IBM-BMT thus seems to be the best strategy for allogeneic BMT, since 1) no GvHD develops even if whole BMCs are injected; 2) no graft failure occurs even if the radiation dose is reduced; 3 ) hemopoietic recovery is rapid and 4) the restoration of $\mathrm{T}$ cell functions is complete even in donor-recipient combinations across MHC barriers [26].

Recently, there have been reports indicating that MSCs secrete a variety of factors that promote tissue repair, stimulate proliferation and differentiation of endogenous tissue progenitors and decrease inflammatory and immune reactions [27-29]. MSCs have been shown to modulate immunological responses via T-cell suppression $[27,29$ 31]. The therapeutic benefit of MSCs extends to T cell-mediated diseases such as GvHD [32], Crohn's disease [33] and the prevention of organ transplantation rejection [34]. Moreover, MSCs have been observed to migrate to the site of injury in acute tissue injuries of kidney [35], liver [36], lung [37] and heart [38]. BMMSCs have the ability to modify and influence almost all the cells of the innate and adaptive immune systems, to interfere with and affect cellular proliferation, differentiation, maturation and function to induce an anti-inflammatory phenotype and to modulate the immune response mediated by BMMSC soluble factors, including IL-6, M-CSF, IL-10, TGF $\beta$, HGF and PGE2 $[29,39,40]$. MSCs modulate DC function, indirectly regulate T and B cell activity, delay and prevent the development of GvHD [41] and suppress DC function during allogeneic islet transplantation [42].

BMMSCs modulate different aspects of the rejection process, including the inhibition of DC differentiation [43], skewing of CD4+ $\mathrm{T}$ helper population phenotypes and modulation of CD8+ cytotoxic T lymphocyte and NK cell functions [20]. BMMSCs strongly inhibited the maturation and functioning of monocyte-derived DCs by interfering selectively with the generation of immature cells via inhibitory mediator of MSC-derived PGE2 [44].

\section{Application of IBM-BMT in Animals}

We have succeeded in treating intractable autoimmune diseases in chimeric-resistant MRL/lpr mice using IBM-BMT [25]. In addition, IBM-BMT can effectively induce organ-specific tolerance, which leads to the success of organ transplantation, including skin [45], pancreas [46], leg [47] and heart [5]. Moreover, donor cell engraftments can be achieved even with reduced radiation doses and without using any immunosuppressants [5]. We previously showed that KK-Ay mice, a type $2 \mathrm{DM}$ model reconstituted with KK-Ay bone marrow cells, showed glycosuria, hyperinsulinemia and hyperlipidemia. However, KK-Ay mice showed improved serum insulin and lipid levels 4 months after $\mathrm{BMT}$ from normal $\mathrm{BALB} / \mathrm{c}$ mice [23]. A previous report suggested that the transplantation of BMMSCs via IBM-BMT in conjunction with the induction of HO- 1 could eradicate type $2 \mathrm{DM}$. The beneficial effect of HO-1 induction further suggests that the abnormality in endothelial progenitor cells is due to a MSC-stromal cell disorder exacerbated by oxidative stress and decreases in adiponectin [48]. IBM-BMT+ thymus 
Citation: Li M, Guo K, Ikehara S (2014) Update on Bone Marrow Collection and Stem Cell Transplantation. J Stem Cell Res Ther 4: 156. doi:10.4172/2157-7633.1000156

\begin{tabular}{|c|c|c|}
\hline & AM & PM \\
\hline Insert times & more & less \\
\hline T cells contamination & high & low \\
\hline Number of hematopoietic progenitors & low & high \\
\hline Ratio of RBC:WBC & high & low \\
\hline Ratio of lymphocyte:granulocyte & high & low \\
\hline
\end{tabular}

Table 1: Comparing AM and PM for Harvesting BMCs.

transplantation (TT) has been shown to induce adiponectin secretion, followed by enhanced pLKB1-AKT-AMPK signaling pathway, upregulation of HO-1 expression, while decreasing iNOS levels in the kidney of $\mathrm{db} / \mathrm{db}$ mice $[49,50]$.

IBM-BMT has become an established method and has already been applied to humans $[51,52]$. IBM-BMT has been reported to be superior to IV-BMT in severe combined immunodeficient mice reconstituted with human cells [53-55]. IBM-BMT can efficiently transfer donor whole BMCs into recipients and this method can therefore be used to quickly replace not only donor-derived-HSCs but also MSCs.

\section{Conclusion}

As discussed, the PM is applicable to the long bones in monkeys but is also applicable to the iliac bones. That no accidents occurred when using the PM to obtain BMCs from either the long bones or the iliac bones in monkeys indicates that both the PM and IBM-BMT are safe and can be applied to humans [56]. The PM can efficiently be used to collect whole BMCs, including HSCs and MSCs, without them being contaminated with T cells, and no GvHD therefore develops. We believe that the combination of the PM and IBM-BMT will become a powerful new strategy for allogenic BMT and regeneration therapy.

\section{Acknowledgments}

We would like to thank Mr. Hilary Eastwick-Field and Ms. Keiko Ando for their help in the preparation of the manuscript.

\section{Conflict of Interests}

None of the authors have conflicts of interest to declare.

\section{References}

1. Thomas ED (1999) Does bone marrow transplantation confer a normal life span? N Engl J Med 341: 50-51.

2. Marmont AM (1994) Immune ablation followed by allogeneic or autologous bone marrow transplantation: a new treatment for severe autoimmune diseases? Stem Cells 12: 125-135.

3. Ikehara S (2001) Treatment of autoimmune diseases by hematopoietic stem cell transplantation. Exp Hematol 29: 661-669.

4. Matsuda KM, Kume A, Ueda Y, Urabe M, Hasegawa M, et al. (1999) Development of a modified selective amplifier gene for hematopoietic stem cell gene therapy. Gene Ther 6: 1038-1044.

5. Guo K, Inaba M, Li M, An J, Cui W, et al. (2008) Long-term donor-specific tolerance in rat cardiac allografts by intrabone marrow injection of donor bone marrow cells. Transplantation 85: 93-101.

6. Kaneda H, Adachi $Y$, Saito $Y$, Ikebukuro K, Machida H, et al. (2005) Longterm observation after simultaneous lung and intra-bone marrow-bone marrow transplantation. J Heart Lung Transplant 24: 1415-1423.

7. Chatzipetrou MA, Mathew JM, Kenyon NS, Esquenazi V, Miller J, et al. (1999) Analysis of post-transplant immune status in recipients of liver/bone marrow allografts. Hum Immunol 60: 1281-1288.

8. Hongo D, Tang X, Dutt S, Nador RG, Strober S (2012) Interactions between NKT cells and Tregs are required for tolerance to combined bone marrow and organ transplants. Blood 119: 1581-1589.

9. Kushida T, Inaba M, Ikebukuro K, Ngahama T, Oyaizu H, et al. (2000) A new method for bone marrow cell harvesting. Stem Cells 18: 453-456.
10. Song C, Hisha H, Wang X, Li Q, Li M, et al. (2008) Facilitation of hematopoietic recovery by bone grafts with intra-bone marrow-bone marrow transplantation. Immunobiology 213: 455-468.

11. Fukui J, Inaba M, Ueda Y, Miyake T, Hosaka N, et al. (2007) Prevention of graft-versus-host disease by intra-bone marrow injection of donor T cells. Stem Cells 25: 1595-1601.

12. Reinders ME, de Fijter JW, Roelofs H, Bajema IM, de Vries DK, et al. (2013) Autologous bone marrow-derived mesenchymal stromal cells for the treatment of allograft rejection after renal transplantation: results of a phase I study. Stem Cells Transl Med 2: 107-111.

13. Thomas ED, Storb R (1970) Technique for human marrow grafting. Blood 36: 507-515.

14. Ikehara S (2011) A novel BMT technique for treatment of various currently intractable diseases. Best Pract Res Clin Haematol 24: 477-483.

15. Dunbar CE (2001) The use of nonhuman primate models to improve gene transfer into haematopoietic stem cells. J Intern Med 249: 329-338.

16. Shields LE, Gaur L, Delio P, Potter J, Sieverkropp A, et al. (2004) Fetal immune suppression as adjunctive therapy for in utero hematopoietic stem cell transplantation in nonhuman primates. Stem Cells 22: 759-769.

17. Lee CC, Fletcher MD, Tarantal AF (2005) Effect of age on the frequency, cell cycle, and lineage maturation of rhesus monkey (Macaca mulatta) CD34+ and hematopoietic progenitor cells. Pediatr Res 58: 315-322.

18. Beard BC, Trobridge GD, Ironside C, McCune JS, Adair JE, et al. (2010) Efficient and stable MGMT-mediated selection of long-term repopulating stem cells in nonhuman primates. J Clin Invest 120: 2345-2354.

19. Izadpanah R, Joswig T, Tsien F, Dufour J, Kirijan JC, et al. (2005) Characterization of multipotent mesenchymal stem cells from the bone marrow of rhesus macaques. Stem Cells Dev 14: 440-451.

20. Devine SM, Bartholomew AM, Mahmud N, Nelson M, Patil S, et al. (2001) Mesenchymal stem cells are capable of homing to the bone marrow of nonhuman primates following systemic infusion. Exp Hematol 29: 244-255.

21. Kushida T, Inaba M, Ikebukuro K, Ichioka N, Esumi T, et al. (2002) Comparison of bone marrow cells harvested from various bones of cynomolgus monkeys a various ages by perfusion or aspiration methods: a preclinical study for human BMT. Stem Cells 20: 155-162.

22. Oyaizu N, Yasumizu R, Miyama-Inaba M, Nomura S, Yoshida H, et al. (1988) (NZW $x$ BXSB)F1 mouse. A new animal model of idiopathic thrombocytopenic purpura. J Exp Med 167: 2017-2022.

23. Than S, Ishida H, Inaba M, Fukuba $Y$, Seino $Y$, et al. (1992) Bone marrow transplantation as a strategy for treatment of non-insulin-dependent diabetes mellitus in KK-Ay mice. J Exp Med 176: 1233-1238.

24. Nishimura M, Toki J, Sugiura K, Hashimoto F, Tomita T, et al. (1994) Focal segmental glomerular sclerosis, a type of intractable chronic glomerulonephritis, is a stem cell disorder. J Exp Med 179: 1053-1058.

25. Kushida T, Inaba M, Hisha H, Ichioka N, Esumi T, et al. (2001) Intra-bone marrow injection of allogeneic bone marrow cells: a powerful new strategy for treatment of intractable autoimmune diseases in MRL/lpr mice. Blood 97: 32923299.

26. Ikehara S (2003) A novel strategy for allogeneic stem cell transplantation: perfusion method plus intra-bone marrow injection of stem cells. Exp Hemato 31: $1142-1146$.

27. Di Nicola M, Carlo-Stella C, Magni M, Milanesi M, Longoni PD, et al. (2002) Human bone marrow stromal cells suppress T-lymphocyte proliferation induced by cellular or nonspecific mitogenic stimuli. Blood 99: 3838-3843.

28. Raffaghello L, Bianchi G, Bertolotto M, Montecucco F, Busca A, et al. (2008) Human mesenchymal stem cells inhibit neutrophil apoptosis: a model for neutrophil preservation in the bone marrow niche. Stem Cells 26: 151-162.

29. Aggarwal S, Pittenger MF (2005) Human mesenchymal stem cells modulate allogeneic immune cell responses. Blood 105: 1815-1822.

30. Krampera M, Glennie S, Dyson J, Scott D, Laylor R, et al. (2003) Bone marrow mesenchymal stem cells inhibit the response of naive and memory antigenspecific T cells to their cognate peptide. Blood 101: 3722-3729.

31. Meisel R, Zibert A, Laryea M, Gobel U, Daubener W, et al. (2004) Human bone marrow stromal cells inhibit allogeneic $\mathrm{T}$-cell responses by indoleamine 2,3-dioxygenase-mediated tryptophan degradation. Blood 103: 4619-4621. 
Citation: Li M, Guo K, Ikehara S (2014) Update on Bone Marrow Collection and Stem Cell Transplantation. J Stem Cell Res Ther 4: 156. doi:10.4172/2157-7633.1000156

32. Li H, Guo Z, Jiang X, Zhu H, Li X, et al. (2008) Mesenchymal stem cells alter migratory property of $T$ and dendritic cells to delay the development of murine lethal acute graft-versus-host disease. Stem Cells 26: 2531-2541.

33. Garcia-OImo D, Garcia-Arranz M, Herreros D, Pascual I, Peiro C, et al. (2005) A phase I clinical trial of the treatment of Crohn's fistula by adipose mesenchymal stem cell transplantation. Dis Colon Rectum 48: 1416-1423.

34. Casiraghi F, Azzollini N, Cassis P, Imberti B, Morigi M, et al. (2008) Pretransplant infusion of mesenchymal stem cells prolongs the survival of a semiallogeneic heart transplant through the generation of regulatory T cells. J Immunol 181: 3933-3946.

35. Kunter U, Rong S, Djuric Z, Boor P, Muller-Newen G, et al. (2006) Transplanted mesenchymal stem cells accelerate glomerular healing in experimental glomerulonephritis. J Am Soc Nephrol 17: 2202-2212.

36. van Poll D, Parekkadan B, Cho CH, Berthiaume F, Nahmias $\mathrm{Y}$, et al. (2008) Mesenchymal stem cell-derived molecules directly modulate hepatocellular death and regeneration in vitro and in vivo. Hepatology 47: 1634-1643.

37. Rojas M, Xu J, Woods CR, Mora AL, Spears W, et al. (2005) Bone marrowderived mesenchymal stem cells in repair of the injured lung. Am J Respir Cell Mol Biol 33: 145-152.

38. Yokokawa M, Ohnishi S, Ishibashi-Ueda H, Obata H, Otani K, et al. (2008) Transplantation of mesenchymal stem cells improves atrioventricula conduction in a rat model of complete atrioventricular block. Cell Transplant 17: $1145-1155$

39. Beyth S, Borovsky Z, Mevorach D, Liebergall M, Gazit Z, et al. (2005) Human mesenchymal stem cells alter antigen-presenting cell maturation and induce T-cell unresponsiveness. Blood 105: 2214-2219.

40. Ramasamy R, Fazekasova H, Lam EW, Soeiro I, Lombardi G, et al. (2007) Mesenchymal stem cells inhibit dendritic cell differentiation and function by preventing entry into the cell cycle. Transplantation 83: 71-76.

41. Zhang B, Liu R, Shi D, Liu X, Chen Y, et al. (2009) Mesenchymal stem cells induce mature dendritic cells into a novel Jagged-2-dependent regulatory dendritic cell population. Blood 113: 46-57.

42. .Aldinucci A, Rizzetto L, Pieri L, Nosi D, Romagnoli P, et al. (2010) Inhibition of immune synapse by altered dendritic cell actin distribution: a new pathway of mesenchymal stem cell immune regulation. J Immunol 185: 5102-5110.

43. Gimble JM, Katz AJ, Bunnell BA (2007) Adipose-derived stem cells for regenerative medicine. Circ Res 100: 1249-1260.

44. Wynn RF, Hart CA, Corradi-Perini C, O'Neill L, Evans CA, et al. (2004) A smal proportion of mesenchymal stem cells strongly expresses functionally active CXCR4 receptor capable of promoting migration to bone marrow. Blood 104: 2643-2645.
45. Ikehara S (2003) New strategies for BMT, organ transplantation, and regeneration therapy. Hematology 8: 77-81.

46. Taira M, Inaba M, Takada K, Baba S, Fukui J, et al. (2005) Treatment of streptozotocin-induced diabetes mellitus in rats by transplantation of islet cells from two major histocompatibility complex disparate rats in combination with intra bone marrow injection of allogeneic bone marrow cells. Transplantation 79: $680-687$.

47. Esumi T, Inaba M, Ichioka N, Kushida T, lida H, et al. (2003) Successful allogeneic leg transplantation in rats in conjunction with intra-bone marrow injection of donor bone marrow cells. Transplantation 76: 1543-1548.

48. Abraham NG, Li M, Vanella L, Peterson SJ, Ikehara S, et al. (2008) Bone marrow stem cell transplant into intra-bone cavity prevents type 2 diabetes: role of heme oxygenase-adiponectin. J Autoimmun 30: 128-135.

49. Li M, Vanella L, Zhang Y, Shi M, Takaki T, et al. (2012) Stem cell transplantation increases antioxidant effects in diabetic mice. Int J Biol Sci 8: 1335-1344.

50. Li M, Abraham NG, Vanella L, Zhang Y, Inaba M, et al. (2010) Successfu modulation of type 2 diabetes in $\mathrm{db} / \mathrm{db}$ mice with intra-bone marrow--bone marrow transplantation plus concurrent thymic transplantation. J Autoimmun 35: $414-423$

51. Li C, He Y, Feng X, Inaba M, Adachi Y, et al. (2007) An innovative approach to bone marrow collection and transplantation in a patient with beta-thalassemia major: marrow collection using a perfusion method followed by intra-bone marrow injection of collected bone marrow cells. Int J Hematol 85: 73-77.

52. Frassoni F, Gualandi F, Podesta M, Raiola AM, Ibatici A, et al. (2008) Direct intrabone transplant of unrelated cord-blood cells in acute leukaemia: a phase I/II study. Lancet Oncol 9: 831-839.

53. Wang J, Kimura T, Asada R, Harada S, Yokota S, et al. (2003) SCIDrepopulating cell activity of human cord blood-derived CD34- cells assured by intra-bone marrow injection. Blood 101: 2924-2931.

54. Yahata T, Ando K, Sato T, Miyatake H, Nakamura Y, et al. (2003) A highly sensitive strategy for SCID-repopulating cell assay by direct injection of primitive human hematopoietic cells into NOD/SCID mice bone marrow. Blood 101: 2905-2913

55. Mazurier F, Doedens M, Gan OIDick JE (2003) Rapid myeloerythroid repopulation after intrafemoral transplantation of NOD-SCID mice reveals a new class of human stem cells. Nat Med 9: 959-963.

56. Inaba M, Adachi Y, Hisha H, Hosaka N, Maki M et al. (2007) Extensive studies on perfusion method plus intra-bone marrow-bone marrow transplantation using cynomolgus monkeys. Stem Cells 25: 2098-2103. 